\title{
Analisis Pengaruh Pelaksanaan Standar Pelayanan Kefarmasian Terhadap Kepuasan Pasien Pada Program Rujuk Balik di Kota Yogyakarta
}

\section{The Influence of Pharmacy Practice Standard Implementation on Pharmacy Community's Patient Satisfaction at Refferal Program in Yogyakarta}

\author{
Novi Dwi R. ${ }^{1}$, Satibi ${ }^{2}$, Diah Ayu $\mathbf{P .}^{3}$ \\ Novi_dwi@ymail.com¹, ${ }^{2}$ satibi@ugm.c.id, 3diahap@yahoo.com \\ ${ }^{123)}$ Magister Manajemen Farmasi, Universitas Gadjah Mada \\ Jalan Sekip Utara Yogyakarta
}

\begin{abstract}
Abstrak
Standar pelayanan kefarmasian sebagai acuan pelaksanaan pelayanan kefarmasian di apotek ditujukan untuk meningkatkan mutu pelayanan kefarmasian.Rujuk Balik merupakan salah satu program BPJS kesehatan untuk penderita penyakit kronis. Obat program ini diambil di apotek diluar biaya kapitasi.Karakteristik individu berhubungan dengan kepuasan. Penelitian ini bertujuan untuk mengetahui pengaruh pelaksanaan standar pelayanan kefarmasian terhadap kepuasan pasien di apotek pada program rujuk balik dan hubungan antara karakteristik dengan kepuasan pasien.

Penelitian ini merupakan penelitian deskriptif analitik dengan metode pengumpulan data dilakukan dengan cara survey.Data diperoleh melalui kuesioner yang berisi karakteristik responden, persepsi responden terhadap pelaksanaan standar pelayanan kefarmasian dan kepuasan Penelitian, dilengkapi data kualitatif hasil wawancara tentang pendapat dan masukan. Lokasi penelitian di apotek Rujuk Balik di Kota Yogkakarta yang berjumlah 4 lokasi dengan sampel yang digunakan sebanyak 101 responden yang terbagi secara proporsional.

Terdapat pengaruh pelaksanaan standar pelayanan kefarmasian terhadap kepuasan pasien di Apotek pada Program Rujuk Balik. Pengaruh signifikan pada aspek pelayanan farmasi klinis $(p=0,000)$ dan sumber daya kefarmasian $(p=0,000)$ sedangkan aspek pengelolaan barang tidak berpengaruh secara signifikan terhadap kepuasan $(p=0,436)$. Karakteristik pasien yang berhubungan dengan kepuasan adalah umur dan jarak antara tempat tinggal dengan apotek, sedangkan karakteristik jenis kelamin, pendidikan, pekerjaan, penyakit tidak berhubungan dengan kepuasan pasien.
\end{abstract}

Kata kunci: standar pelayanan kefarmasian, Apotek Program Rujuk Balik

\section{Abstract}

The Pharmaceutical services standards as an implementation reference of Pharmaceutical services in the pharmacy is intended to improve 
the quality of pharmaceutical services. Referral program is one BPJS health program for people with chronic diseases. The drugs for this program are taken in pharmacies outside the capitation fee system claims. The Quality of services affects patient satisfaction. Individual characteristics associated with satisfaction. This study aims to determine the effect of the implementation of the standard pharmaceutical services on the satisfaction and the relationship between the characteristics and the patient satisfaction in the pharmacies in the Referral Program.

This research is descriptive analytic method of data collection is done by survey. Data obtained through a questionnaire which contains characteristics of respondents, respondents' perceptions of the implementation of pharmaceutical service standards and satisfaction. The research is supported with qualitative data as the results of interviews about opinions and input. The location of the research is in referral pharmacy in Yogyakarta with the samples as many as 101 respondents that were divided proportionally.

There is the influence of the standard implementation of pharmaceutical services to the satisfaction of the patient in the pharmacy at Referral Program. Significant influence on the clinical aspects of pharmaceutical services $(p=0.000)$ and pharmaceutical resource $(p=$ 0.000 ) while the aspects of the supplies management were not significant ( $p$ $=0.436)$. Patient characteristics associated with the satisfaction were age and the distance between the residence and the pharmacy, while the characteristics of gender, education, employment, disease were not related with the patient satisfaction.

\section{Keywords: pharmaceutical service standard, Referral Pharmacy} Program

\section{Pendahuluan}

Pengaturan standar pelayanan kefarmasian di apotek bertujuan untuk meningkatkan mutu pelayanan kefarmasian (Menteri Kesehatan, 2014). Kepuasan tergantung pada kualitas barang atau jasa, semakin tinggi kualitas semakin tinggi tingkat kepuasan pelanggan (Kotler dan Keller, 2009). Karakteristik sosiodemografi mempengaruhi kepuasan pasien meliputi: umur, pendidikan, status kesehatan, ras, status perkawinan dan kelas sosial (Naidu, 2009).

Standar pelayanan kefarmasian meliputi standar pengelolaan sediaan farmasi dan pelayanan farmasi klinis, didukung oleh ketersediaan sumber daya kefarmasian dengan jaminan mutu pelayanan kefarmasian (Menteri Kesehatan, 2014). Pelaksanaan standar pelayanan kefarmasian menurut persepsi apoteker di kota yogyakarta 21\% baik. (Atmini dkk., 2011), sedangkan di kabupaten sleman sudah melakukan implementasi standar pelayanan kefarmasian namun belum sepenuhnya dilakukan dengan optimal (Istiqomah dan Satibi, 2012)
Pelayanan Program Rujuk Balik diberikan kepada peserta penderita penyakit kronis, khususnya penyakit diabetis melitus, hipertensi, jantung, asma, penyakit paru obstruksi kronik (PPOK), epilepsy, stroke, schizophrenia, Systemic Lupus Eythematosus (SLE), yang sudah terkontrol dan stabil namun masih memerlukan pengobatan atau asuhan keperawatan jangka panjang, obat program rujuk balik diperoleh melalui apotek atau depo farmasi fasilitas kesehatan tingkat pertama yang bekerja sama dengan BPJS (Badan Penyelenggara Jaminan Sosial Kesehatan, 2014).

Berdasarkan latar belakang diatas penelitian ini dilakukan dengan tujuan untuk mengetahui pengaruh pelaksanaan standar pelayanan kefarmasian terhadap kepuasan pasien pada program rujuk balik dan mengetahui hubungan karakteristik dengan kepuasan pasein. Hasil penelitian diharapkan dapat memberikan masukan dalam peningkatan pelaksanaan standar pelayanan kefarmasian di apotek dan peningkatan kualitas pelayanan program rujuk balik.dalam sistem jaminan kesehatan nasional. 


\section{Metode Penelitian}

Penelitian merupakan penelitian non eksperimental yang bersifat deskriptif analitik. Data diperoleh dari responden apoteker dan responden pasien. Data dengan responden apoteker di apotek rujuk balik untuk mengetahui gambaran implementasi oleh apoteker. Data dengan responden pasien untuk mengetahui pengaruh persepsi pasien tentang implementasi standar pelayanan kefarmasian terhadap kepuasan dan hubungan karakteristik pasien dengan kepuasan.

Penilaian gambaran implementasi standar pelayanan kefarmasian oleh apotek dilakukan dengan menggunakan kuesioner dan wawancara secara langsung kepada salah satu apoteker di apotek pada empat apotek Program Rujuk Balik di Kota Yogyakarta. Kuesioner menggunakan skala Likert dengan skala 5. Data yang didapat diolah untuk menghitung skor, Skor pelaksanaan tiap aspek didapat dengan rumus:

\section{Skor Tiap Aspek}

$=\frac{\sum \text { Skor tiap aspek }}{\Sigma \text { Skor Maksimal tiap aspek }} \times 100$

Skor Pelaksanaan standar $=\frac{\Sigma \text { Skor semua aspek }}{\Sigma \text { Aspek }} \times 100$

Total skor diinterpretasikan ke dalam tiga kategori yaitu baik dengan rentang nilai 81\% - 100, cukup dengan rentang nilai 61-80, dan kurang jika nilai $\leq$ 60

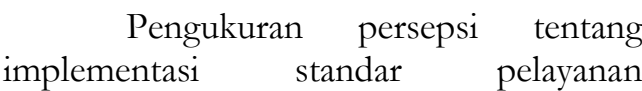
kefarmasian dan kepuasan oleh responden dilakukan dengan kuesioner dengan skala Likert dengan skala piihan 5 dilengkapi data karakteristik responden. Teknik pengambilan data dengan survey menyebarkan kuesioner kepada responden dan wawancara mendalam. Penelitian dilakukan di apotek yang melayani program rujuk balik di kota Yogyakarta. Sampel yang digunakan 101 responden dengan metode pengambilan sampel yang digunakan adalah proportional random sampling di 4 Apotek Rujuk balik. Subyek penelitian adalah pasien Program Rujuk Balik. Jumlah sampel dihitung berdasarkan rumus Slovin (Sunyoto, 2014):

$$
n=\frac{N}{1+N e^{2}}
$$

Jumlah sampel $n$ yang digunakan untuk penelitian dengan jumlah populasi $N$ dengan Margin error . Menurut data BPJS Kesehatan cabang utama Yogyakarta jumlah pasien program rujuk balik yang melakukan pengambilan obat di apotek sebesar 2.550, sehingga dengan margin eror $10 \%$ sampel minimal yang digunakan sebesra 97, dalam penelitian ini digunakan jumlah sampel 101, jumlah masing-masing sampel tiap apotek ditentukan secara proporsional (tabel I).

Tabel I. Jumlah Sampel Penelian

\begin{tabular}{llcc}
\hline No & Nama Apotek & Jumlah Pasien & Jumlah Sampel \\
\hline $\mathbf{1}$ & Apotek Medikatama 1 & 1.500 & 59 \\
$\mathbf{2}$ & Apotek Medikatama 2 & 800 & 32 \\
$\mathbf{3}$ & Apotek Ramadan & 200 & 8 \\
$\mathbf{4}$ & Apotek UGM & 50 & 2 \\
\hline & & 2.550 & 101 \\
\hline
\end{tabular}


Tabel II. Karakteristik Responden

\begin{tabular}{|c|c|c|c|}
\hline & Karakteristik & $\begin{array}{c}\text { Jumlah } \\
\text { Responden }\end{array}$ & Prosentase \\
\hline Jenis & Laki-laki & 48 & $47,52 \%$ \\
\hline Kelamin: & Perempuan & 53 & $52,48 \%$ \\
\hline Pendidikan & Tidak Sekolah & 0 & 0 \\
\hline \multirow[t]{6}{*}{ terakhir } & $\mathrm{SD}$ & 4 & $3,96 \%$ \\
\hline & SMP & 7 & $6,93 \%$ \\
\hline & SMU & 35 & $34,65 \%$ \\
\hline & Akademi/D3 & 12 & $11,88 \%$ \\
\hline & Sarjana & 39 & $38,61 \%$ \\
\hline & Lain-lain & 4 & $3,96 \%$ \\
\hline \multirow[t]{8}{*}{ Pekerjaan } & Tidak bekerja & 19 & $18,81 \%$ \\
\hline & TNI/Polri & 0 & $0 \%$ \\
\hline & PNS & 16 & $15,84 \%$ \\
\hline & Pegawai Swasta & 1 & $0,99 \%$ \\
\hline & Wiraswasta & 5 & $4,95 \%$ \\
\hline & Petani & 0 & $0 \%$ \\
\hline & Pensiunan & 59 & $58,42 \%$ \\
\hline & Lainnya & 1 & $0,99 \%$ \\
\hline \multirow[t]{6}{*}{ Umur } & Kurang dari 20 tahun & 0 & $0 \%$ \\
\hline & Lebih dari 20 th s/d 30 th & 0 & $0 \%$ \\
\hline & Lebih dari 30 th s/d 40 th & 1 & $0,99 \%$ \\
\hline & Lebih dari 40 th s/d 50 th & 7 & $6,93 \%$ \\
\hline & Lebih dari 50 th s/d 60 th & 25 & $24,75 \%$ \\
\hline & Lebih dari 60 th & 68 & $67,33 \%$ \\
\hline \multirow{10}{*}{$\begin{array}{l}\text { Penyakit } \\
\text { yang diderita }\end{array}$} & Diabetis Melitus & 31 & $30,69 \%$ \\
\hline & Hipertensi & 37 & $36,63 \%$ \\
\hline & Jantung & 2 & $1,98 \%$ \\
\hline & Asma & 1 & $0,99 \%$ \\
\hline & Penyakit Paru Obstruksi Kronik & 0 & $0 \%$ \\
\hline & Epilepsi & 0 & $0 \%$ \\
\hline & Schizophrenia & 0 & $0 \%$ \\
\hline & Stroke & 1 & $0,99 \%$ \\
\hline & Systemic Lupus Erythematosus & 0 & $0 \%$ \\
\hline & Komplikasi (penyakit lebih dari 1) & 29 & $28,71 \%$ \\
\hline \multirow{5}{*}{$\begin{array}{l}\text { Lama } \\
\text { menjadi } \\
\text { peserta rujuk } \\
\text { balik }\end{array}$} & Kurang dari 3 bulan & 5 & $4,95 \%$ \\
\hline & Lebih dari 3 bulan s/d 6 bulan & 2 & $1,98 \%$ \\
\hline & Lebih dari $6 \mathrm{~s} / \mathrm{d} 9$ bulan & 2 & $1,98 \%$ \\
\hline & Lebih dari 9 bulan s/d 12 bulan & 7 & $6,93 \%$ \\
\hline & Lebih dari 12 bulan & 85 & $84,16 \%$ \\
\hline \multirow{5}{*}{$\begin{array}{l}\text { Jarak tempat } \\
\text { tinggal } \\
\text { dengan } \\
\text { apotek }\end{array}$} & Kurang dari $500 \mathrm{~m}$ & 14 & $13,59 \%$ \\
\hline & Lebih dari $500 \mathrm{~m} \mathrm{~s} / \mathrm{d} 1 \mathrm{Km}$ & 28 & $27,72 \%$ \\
\hline & Lebih dari $1 \mathrm{Km} \mathrm{s} / \mathrm{d} 3 \mathrm{Km}$ & 23 & $22,77 \%$ \\
\hline & Lebih dari $3 \mathrm{Km} \mathrm{s} / \mathrm{d} 5 \mathrm{Km}$ & 23 & $23,77 \%$ \\
\hline & Lebih dari $5 \mathrm{Km}$ & 13 & $12,87 \%$ \\
\hline
\end{tabular}

\section{Hasil dan Pembahasan}

\section{Analisis Deskriptif}

\section{Karakteristik Responden}

Penelitian ini menggunakan responden sebanyak 101 pasien program rujuk balik yang tersebar di empat apotek di Kota Yogyakarta. Karakteristik responden disajikan pada tabel II.

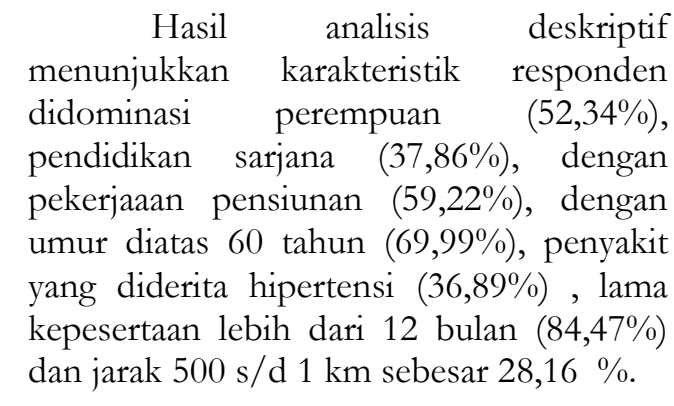




\author{
Gambaran Pelaksanaan Standar \\ Pelayanan Kefarmasian oleh Apotek \\ Rujuk Balik
}

Gambaran pelaksanaan standar pelayanan kefarmasian oleh apoteker di Apotek Rujuk Balik disajikan pada tabel III

Tabel III.Gambaran Pelaksanaan Standar Pelayanan Kefarmasian oleh Apotek

\begin{tabular}{llcccc}
\hline No & \multicolumn{1}{c}{ ASPEK } & $\begin{array}{c}\text { MEDIKATAMA } \\
\text { Mengelolaan }\end{array}$ & $\begin{array}{c}\text { MEDIKATAMA } \\
\text { RAMADHAN }\end{array}$ & UGM \\
\hline $\mathbf{1}$ & $\begin{array}{l}\text { Pe,79 } \\
\text { Barang }\end{array}$ & & 77,94 & 89,80 & 100 \\
$\mathbf{2}$ & $\begin{array}{l}\text { Pelayanan } \\
\text { Farmasi Klinis }\end{array}$ & 49,52 & 52,38 & 78,10 & 77,14 \\
$\mathbf{3}$ & $\begin{array}{l}\text { Sumber Daya } \\
\text { Kefarmasian }\end{array}$ & 91,39 & 89,72 & 95,56 & 99,72 \\
$\mathbf{4}$ & $\begin{array}{l}\text { Evaluasi } \\
\text { Mutu }\end{array}$ & 76,67 & 56,67 & 90,00 & 96,67 \\
& $\begin{array}{l}\text { Skor } \\
\text { KATEGORI }\end{array}$ & CUKUP & CUKUP & BAIK & BAIK \\
\hline
\end{tabular}

\section{Aspek Pengelolaan Barang}

Aspek pengelolaan barang meliputi: perencanaan, pengadaan, penerimaan, penyimpanan, pemusnahan, pengendalian dan pencatatan dan pelaporan (Menteri Kesehatan, 2014). Aspek pengelolaan barang di empat apotek rujuk balik dilakukan dengan baik dengan nilai aspek pengelolaan barang dengan nilai Apotek UGM 100, Apotek Ramadhan 89,79, Apotek Medikatama 1 86,79 dan Apotek Medikatama 2 77,94. Pengelolaan barang yang optimal dilakukan pada proses perencanaan, pengadaan, penerimaan, penyimpanan dan pemusnahan, sedangkan proses yang belum dilakukan secara optimal apotek Medikatama 1 dan Medikatama 2 adalah proses pengendalian, pencatatan dan pelaporan, hal ini disebabkan tidak ada dukungan Sistem informasi Manajemen pada proses tersebut dan masih dilakukan secara manual berdasarkan intuisi.

\section{Aspek Pelayanan Farmasi Klinis}

Aspek pelayanan farmasi klinis meliputi Skrining resep, dispensing, Pelayanan Informasi Obat, Konseling, Home Care, Pemantauan Terapi Obat dan Monitoring Efek Samping Obat (Menteri Kesehatan, 2014). Hasil prosentase pelaksanaan aspek farmasi klinis: Apotek Ramadhan 78,10, UGM 77,14, Medikatama 2 52,38 dan Medikatama 1
49,52. Pelayanan farmasi klinis dibutuhkan peran apoteker, apotek dengan jumlah apoteker yang terbatas memberikan nilai pelaksanaan aspek farmasi klinis yang rendah. Pelaksanaan farmasi klinis yang belum dapat dilaksanakan dengan baik meliputi kegiatan: Home Care, Pemantauan Terapi Obat dan Monitoring Efek Samping Obat.

\section{Aspek Sumber Daya Kefarmasian}

Aspek Sumber daya kefarmasian meliputi aspek Sumber Daya Manusia dan Aspek Sarana Prasarana (Menteri Kesehatan, 2014). Hasil Skor untuk Aspek Sumber Daya Kefarmasian Apotek UGM 99,72, Ramadhan 95,56, Medikatama 1 91,39 dan Medikatama 2 89,72. Semua apotek Program Rujuk Balik telah menyediakan sumber Daya Kefarmasian dengan baik, namun masih perlu diperbaiki dalam kecukupan jumlah apoteker dan perbaikan sarana prasarana yang ditujukan untuk kenyamanan pasien.

\section{Aspek Evaluasi Mutu}

Aspek Evaluasi Mutu meliputi: Evaluasi mutu manajerial dan mutu pelayanan farmasi klinis (Menteri Kesehatan, 2014). Hasil Skor Evaluasi mutu Apotek UGM 96,67, Ramadhan 90,00, Medikatama 1 76,67 dan Medikatama 2 56,67. Kegiatan apotek dalam menjamin mutu manajerial dengan 
audit keuangan, review moving obat dan observasi terhadap penyimpanan obat. Mutu pelayanan farmasi klinis dilakukan dengan survey kepuasan pelanggan dan membuat Standar Operasional Prosedur untuk kegiatan pelayanan farmasi klinis dan kontrol terhadap lama waktu layanan. Pelaksanaan evaluasi mutu belum dilakukan rutin dan terdokumentasi dengan baik. \begin{tabular}{l} 
Analisis Pengaruh Pelaksanaan Standar \\
Pelayanan Kefarmasian \\
Kepuasan \\
\multicolumn{2}{c}{ Pengaruh }
\end{tabular}

Pengaruh variabel bebas pelaksanaan standar pelayanan kefarmasian di apotek terhadap variabel terikat kepuasan pasien dianalisis dengan analisis regresi linier berganda. Nilai signifikansi sebesar $<5 \%$ menunjukkan variabel pelaksanaan standar pelayanan kefarmasian berpengaruh signifikan terhadap Kepuasan.

Tabel IV. Analisis Regresi Linier Berganda Pengaruh Pelaksanaan Standar Pelayanan Kefarmasian Terhadap Kepuasan

\begin{tabular}{|c|c|c|c|c|c|c|}
\hline $\begin{array}{c}\text { Variabel } \\
\text { Tergantung }\end{array}$ & \multicolumn{2}{|c|}{ Variabel Bebas } & B & $\mathrm{P}$ & $\begin{array}{c}\text { Nilai Sig F } \\
\text { pada } \\
\text { ANOVA }\end{array}$ & $\mathrm{R} 2$ \\
\hline \multirow{6}{*}{$\begin{array}{l}\text { Kepuasan } \\
\text { Pasien }\end{array}$} & Standar & Konstan & 11,782 & 0,001 & 0,000 & 0,631 \\
\hline & Pelayanan & Pengelolaan & $-0,220$ & 0,285 & & \\
\hline & Kefarmasian & Barang & & & & \\
\hline & & Pelayanan & 0,201 & 0,041 & & \\
\hline & & Farmasi Klinis & & & & \\
\hline & & SD Kefarmasian & 0,654 & 0,000 & & \\
\hline
\end{tabular}

Pengaruh pelaksanaan standar pelayanan kefarmasian secara simultan yang terdiri dari aspek pengelolaan barang, pelayananan farmasi klinis dan sarana prasarana berpengaruh terhadap kepuasan dengan nilai $p=0,000(p<0,5)$. Salah satu tujuan pengaturan standar adalah meningkatkan mutu layanan kefarmasian (Menteri Kesehatan, 2014). Ada hubungan antara kualitas pelayanan kesehatan dengan pengguna askes sosial pada pelayanan rawat inap (Bata dkk., 2013). Usaha peningkatan mutu layanan kefarmasian yang berpengaruh signifikan terhadap kepuasan pasien adalah variabel pelayanan farmasi klinis dan sumber daya kefarmasian. Pengelolaan barang tidak berpengaruh signifikan terhadap kepuasan pasien. Analisis pengaruh masing-masing aspek standar pelayanan kefarmasian di apotek digunakan analisis regresi linier sederhana. Masing-masing aspek pelaksanaan standar pelayanan kefarmasian di Apotek selanjutnya dilakukan analisis regresi linier sederhana. Hasil analisis disajikan pada tabel $\mathrm{V}$.

\section{Analisis Pengaruh Pengelolaan Barang Terhadap Kepuasan \\ Analisis dilakukan untuk} mengetahui pengaruh variabel pengelolaan barang terhadap kepuasan pasien. Hasil analisis nilai sig 0,436 $(>0,05)$ artinya tidak terdapat pengaruh signifikan antara pengelolaan barang dengan kepuasan. Pengelolaan barang yang dinilai dari jaminan ketersediaan jumlah dan kualitas obat yang diterima responden tidak mempengaruhi kepuasan. Apotek program rujuk balik selalu menyediakan obat yang dibutuhkan dengan sumber pengadaan resmi sehingga kualitas dan ketersediaannya terjamin, persepsi responden terhadap pengelolaan barang yang baik tidak diikuti tingginya kepuasan. Responden mempunyai persepsi bahwa ketersediaan barang merupakan hal yang memang seharusnya dilakukan. Dari pendapat yang disampaikan 78 responden menyatakan prosedur pengambilan obat sudah baik. Apotek berusaha menyediakan obat sesuai harga e-catalog meskipun tidak dapat melakukan akses terhadap $e$ procurement yang dikembangkan BPJS. 
Tabel V. Analisis Regresi Linier Sederhana Pengaruh Aspek-aspek Standar Pelayanan Kefarmasian Terhadap Kepuasan

\begin{tabular}{|c|c|c|c|c|c|c|}
\hline $\begin{array}{l}\text { Variabel } \\
\text { Tergantung }\end{array}$ & $\begin{array}{l}\text { Variabel } \\
\text { Bebas }\end{array}$ & B & & $\mathrm{r}$ & $\mathrm{p}$ & Interpretasi Hasil \\
\hline \multirow{6}{*}{$\begin{array}{l}\text { Kepuasan } \\
\text { Pasien }\end{array}$} & Pengelolaan & 35,662 & $-0,230$ & 0,078 & 0,436 & $\mathrm{p}>0,05$ \\
\hline & Barang & & & & & $\begin{array}{c}\text { Tidak terdapat } \\
\text { pengaruh signifikan } \\
\text { dari pengelolaan } \\
\text { barang terhadap } \\
\text { kepuasan pasien }\end{array}$ \\
\hline & Pelayanan & 22,448 & 0,673 & 0,654 & 0,000 & $\mathrm{p}<0,05$ \\
\hline & Farmasi Klinis & & & & & $\begin{array}{l}\text { terdapat pengaruh } \\
\text { signifikan dari } \\
\text { pelayanan farmasi } \\
\text { klinis dengan } \\
\text { kepuasan pasien }\end{array}$ \\
\hline & $\mathrm{SD}$ & 6,991 & 0,783 & 0,771 & 0.000 & $\mathrm{p}<0,05$ \\
\hline & Kefarmasian & & & & & $\begin{array}{l}\text { terdapat pengaruh } \\
\text { signifikan dari } \\
\text { pelayanan farmasi } \\
\text { klinis dengan } \\
\text { kepuasan pasien }\end{array}$ \\
\hline
\end{tabular}

\section{Analisis Pengaruh Pelayananan Farmasi Klinis Terhadap Kepuasan}

Analisis dilakukan untuk mengetahui pengaruh variabel pelayanan farmasi klinis terhadap kepuasan pasien. Hasil analisis nilai sig $0,000(<0,05)$ artinya terdapat pengaruh signifikan antara sumber daya kefarmasian dengan kepuasan. Dari analisis regresi linier sederhana diperoleh nilai r sebesar 0,783 pengaruh sumber daya kefarmasian memiliki pengaruh kuat terhadap kepuasan pasien.

Pelayanan farmasi klinis meliputi: pengkajian resep, dispensing, Pelayanan Informsi Obat, konseling, home care, pemantauan terapi obat dan monitoring efek samping obat (Menteri Kesehatan, 2014). Pelayanan kefarmasian ini berpengaruh signifikan terhadap terhadap kepuasan pasien. Apoteker yang merupakan ujung tombak dalam pelayanan kefarmasian di apotek harus meningkatkan perannya. Kewajiban apoteker untuk memberikan pelaynan kefarmasian belum sepenuhnya dilakukan di apotek di kota Yogyakarta (Atmini dkk., 2011).

\section{Analisis Pengaruh Sumber Daya Kefarmasian Terhadap Kepuasan}

Analisis dilakukan untuk mengetahui pengaruh variabel sumber daya kefarmasian terhadap kepuasan pasien. Hasil analisis nilai sig $0,000(<0,05)$ artinya terdapat pengaruh signifikan antara sumber daya kefarmasian dengan kepuasan. Dari analisis regresi linier sederhana diperoleh nilai $r$ sebesar 0,771 pengaruh pelayanan farmasi klinis memiliki pengaruh kuat terhadap kepuasan pasien.

Sumber daya kefarmasian yang meliputi sumber daya manusia dan sarana prasarana merupakan bagian dari dimensi Tangible. Berdasarkan penelitian yang dilakukan oleh (Hidayati dkk., 2014), ada hubungan antara kualitas pelayanan kesehatan (Reability, Assurance, Tangible, Emphaty, Responsveneses) dengan kepuasan pasien pengguna Askes Sosial pada pelayanan rawat inap RSUD Lakipada Kabupaten Tana Toraja tahun 2013.

\section{Analisis Hubungan Karakteristik Pasien dengan Kepuasan}

Analisis hubungan karakteristik pasien dengan kepuasan dilakukan untuk melihat ada tidaknya hubungan antara karakteristik pasien dengan tingkat kepuasan pasien. Data dianalisis dengan analisis kendal tau atau spearmen. Hasil analisis hubungan karakteristik pasien dengan kepuasan disajikan pada tabel VI. 
Tabel VI. Analisis Hubungan Karakteristik responden dengan Kepuasan

\begin{tabular}{|c|c|c|c|c|c|}
\hline $\begin{array}{l}\text { Variabel } \\
\text { Terikat }\end{array}$ & $\begin{array}{c}\text { Variabel } \\
\text { Bebas }\end{array}$ & Analisis & Sig & $\begin{array}{c}\text { Koefisien } \\
\text { Korelasi }\end{array}$ & Interpretasi Hasil \\
\hline Kepuasan & Jenis Kelamin & Kendal Tau & 0,160 & $-0,116$ & $\begin{array}{l}\text { Sig }>0,05 \\
\text { tidak terdapat hubungan } \\
\text { antara jenis kelamin dengan } \\
\text { kepuasan }\end{array}$ \\
\hline $\begin{array}{l}\text { Variabel } \\
\text { Terikat }\end{array}$ & $\begin{array}{c}\text { Variabel } \\
\text { Bebas }\end{array}$ & Analisis & Sig & $\begin{array}{c}\text { Koefisien } \\
\text { Korelasi }\end{array}$ & Interpretasi Hasil \\
\hline \multirow[t]{6}{*}{ Kepuasan } & Pendidikan & Spearman & 0,132 & 0,149 & $\begin{array}{l}\text { Sig }>0,05 \\
\text { tidak terdapat hubungan } \\
\text { antara pendidikan dengan } \\
\text { kepuasan }\end{array}$ \\
\hline & Pekerjaan & Kendal Tau & 0,060 & $-0,148$ & $\begin{array}{l}\text { Sig }>0,05 \\
\text { tidak terdapat hubungan } \\
\text { antara pendidikan dengan } \\
\text { kepuasan }\end{array}$ \\
\hline & Umur & Spearman & 0,003 & $-0,298$ & $\begin{array}{l}\text { Sig }<0,05 \\
\text { terdapat hubungan yang } \\
\text { signifikan antara Umur } \\
\text { dengan kepuasan* }\end{array}$ \\
\hline & Penyakit & Kendal Tau & 0,998 & 0,000 & $\begin{array}{l}\text { Sig }>0,05 \\
\text { tidak terdapat hubungan } \\
\text { antara penyakit dengan } \\
\text { kepuasan }\end{array}$ \\
\hline & $\begin{array}{c}\text { Lama } \\
\text { Kepesertaan }\end{array}$ & Spearman & 0,748 & $-0,032$ & $\begin{array}{l}\text { Sig }>0,05 \\
\text { tidak terdapat hubungan } \\
\text { antara lama kepesertaan } \\
\text { dengan kepuasan }\end{array}$ \\
\hline & Jarak & Spearman & 0,004 & $-0,286$ & $\begin{array}{l}\text { Sig }<0,05 \\
\text { terdapat hubungan yang } \\
\text { signifikan antara Umur } \\
\text { dengan kepuasan* }\end{array}$ \\
\hline
\end{tabular}

Hasil analisis hubungan karakteristik pasien dengan kepuasan menunjukkan bahwa terdapat hubungan yang signifikan antara umur dan jarak dengan kepuasan sedangkan untuk karakteristik jenis kelamin, pendidikan, pekerjaan dan penyakit tidak terdapat hubungan yang signifikan dengan kepuasan. Prosedur pelayanan

Program Rujuk Balik membuat pasien lebih sering menggunakan fasilitas pelayanan kesehatan sehingga terdapat hubungan antara usia dan jarak terhadap kepuasan. Hal tersebut dikarenakan semakin tua usia responden dan semakn jauh jarak dengan fasilitas maka semakin terbatas kemampuannya mengakses fasilitas pelayanan kesehatan dan berpengarus terhadap kepuasannya.

Karakteristik Jenis kelamin, pendidikan, pekerjaan, penyakit dan lama kepesertaan tidak berhubungan dengan kepuasan Prosedur pelayanan pasien berlaku untuk semua peserta tanpa membedakan jenis kelamin, pendidikan, pekerjaan dan lama kepesertaan. Pelayanan kefarmasian di Apotek memberikan perhatian yang sama untuk semua peserta.

\section{Simpulan}

Terdapat pengaruh pelaksanaan standar pelayanan kefarmasian dengan kepuasan pasien di Apotek pada Program Rujuk Balik Sistem Jaminan kesehatan nasional dan tidak terdapat pengaruh pengelolaan barang dengan kepuasan. Terdapat pengaruh pelayanan kefarmasian dengan kepuasan dan terdapat pengaruh sumber daya kefarmasian dengan kepuasan serta terdapat hubungan antara karaketristik usia dan jarak dengan kepuasan, dan tidak terdapat hubungan antara karakteristik jenis kelamin, pendidikan, pekerjaan, umur, penyakit yang diderita dan lama kepesertaan dengan kepuasan. 


\section{Ucapan Terimakasih}

Pada kesempatan ini, peneliti ingin mengucapkan terima kasih yang sedalamdalamnya kepada Apotek Rujuk Balik di kota Yogyakarta dan Program Profesi Apoteker UII Yogyakarta sehingga penelitian ini dapat selesai dengan lancar.

\section{Daftar Pustaka}

Atmini, K.., Gandjar, I., G., dan Purnomo, A., 2011. Analisi Aplikasi Standar Pelayanan Kefarmasian di Apotek Kota Yogyakarta. Jurnal Manajemen dan Pelayanan Farmasi, 1: .

Badan Penyelenggara Jaminan Sosial Kesehatan, 2014. Peraturan Badan Penyelenggara Jaminan Sosial Kesehatan Nomor 1 Tahun 2014 Tentang Penyelenggaraan Jaminan Kesehatan.

Bata, Y.W., Arifin, M.A., dan Darmawansyah, 2013. Hubungan Kualitas Pelayanan Kesehatan dengan Kepuasan Pasien Pengguna Askes Sosial pada Pelayanan Rawat Inap Di RSUD Lakipadada Kabupaten Tana Toraja Tahun 2013. Fakultas Kesehatan Masyarakat, Universitas Hasanudin, .
Hidayati, A.N., Suryawati, C., dan Sriatmi, A., 2014. Analisis Hubungan Karakteristik Pasien Dengan Kepuasan Pelayanan Rawat Jalan Semarang Eye Center (SEC) Rumah Sakit Islam Sultan Agung Semarang. Jurnal Kesehatan Masyarakat, 2: .

Istiqomah, F.N. dan Satibi, 2012. Evaluasi Implementasi Standar Pelayanan Kefarmasian Oleh Apoteker. Jurnal Manajemen dan Pelayanan Farmasi, 2: 127-132.

Kotler, P. dan Keller, K.L., 2009. Manajemen Pemasaran, 13th ed. Penerbit Erlangga, Jakarta.

Menteri Kesehatan, (first), 2014. Peraturan Menteri Kesehatan Republik Indonesia Nomor 35 Tahun 2014. Jakarta.

Naidu, A., 2009. Factors affecting patient satisfaction and healthcare quality. International Journal of Health Care Quality Assurance, 22: 377.

Sunyoto, D., 2014. Konsep Dasar Riset Pemasaran Dan Perilaku Konsumen. CAPS (Center for Academic Publishing Services), Yogyakarta. 